\title{
Effects of Exposure In Utero to Bisphenol A on the Expression of Aryl Hydrocarbon Receptor, Related Factors, and Xenobiotic Metabolizing Enzymes in Murine Embryos
}

\author{
Hanako NISHIZAWA ${ }^{1)}$, Satoshi IMANISHI ${ }^{2)}$ and Noboru MANABE1) \\ ${ }^{1)}$ Research Unit for Animal Life Sciences, Animal Resource Science Center, Graduate School of \\ Agricultural and Life Sciences, The University of Tokyo, Ago 3145, Ibaraki-Iwama 319-0206, \\ and ${ }^{2)}$ Unit of Anatomy and Cell Biology, Department of Animal Sciences, Kyoto University, \\ Kyoto 606-8502, Japan
}

\begin{abstract}
To evaluate the effects of bisphenol A (BPA), a candidate endocrine disruptor (ED), on embryonic development, we examined the mRNA expression levels of the aryl hydrocarbon receptor (AhR; which binds with many EDs and plays crucial roles in their metabolism) and related factors [aryl hydrocarbon receptor repressor (AhRR) and AhR nuclear translocator (Arnt)], xenobiotic metabolizing enzymes [XMEs; cytochrome P450 1A1 (CYP1A1) and UDP-glucuronosyltransferase, and the glutathione $S$-transferase Ya subunit (GST)], in murine embryos exposed in utero to BPA (0.02, 2,200 , and $20,000 \mu \mathrm{g} / \mathrm{kg} /$ day) and $17 \beta$-estradiol (E2; $5 \mu \mathrm{g} / \mathrm{kg} /$ day, used as a positive control) at $6.5-$ 13.5 or $6.5-17.5$ days post coitum (dpc) using the quantitative real-time reverse transcriptionpolymerase chain reaction (RT-PCR) method. Protein levels of CYP1A1 and GST in embryonic livers were estimated by Western immunoblotting. Exposure in utero to BPA [0.02 (1/100 dose of environmental exposure), 2, 200, and 20,000 $\mu \mathrm{g} / \mathrm{kg} /$ day] increased AhR mRNA expression in the cerebra, cerebella, and gonads (testes and ovaries) of male and female mid- and late-developmental stage (14.5- and 18.5-dpc, respectively) embryos. BPA dose-independently up-regulated the expression of AhRR and Arnt in mid- and late-stage embryos. BPA had no remarkable effect on the mRNA levels of XMEs in mid-stage embryos, but dose-dependently up-regulated the expression in late-stage embryos. Moreover, the protein levels of these enzymes in the livers of late-stage embryos were increased. The present findings revealed that exposure to BPA in utero disrupts the expression of $\mathrm{AhR}$ and related factors and of xenobiotic metabolizing enzymes, and that mid-stage embryos, in the organogenic stage, are sensitive to BPA.

Key words: Aryl hydrocarbon receptor (AhR), AhR relating factor, Bisphenol A (BPA), Murine embryo, Xenobiotic metabolizing enzymes (XMEs)
\end{abstract}

(J. Reprod. Dev. 51: 593-605, 2005)

B isphenol A [BPA; 2,2-bis (4-hydroxyphenyl) propane], which is composed of two benzene rings and in conformation resembles a synthetic estrogen, diethylstilbestrol (DES), is a common plasticizer for polycarbonate and epoxy resins and

Accepted for publication: May 12, 2005

Correspondence: N. Manabe (e-mail: amanabe@mail.ecc.utokyo.ac.jp) a candidate environmental endocrine disruptor (ED) $[1,2]$. BPA has toxicological effects on the reproductive, immunological, and nervous systems in mammals, binds with estrogen receptor- $\alpha(\mathrm{ER} \alpha$; NR3A1) and ER- $\beta$ (NR3A2), and induces estrogenic activity [3-6]. BPA affects the expression levels of ERs and ER-like nuclear receptor mRNAs in the rat uterus [6], but the mechanism of its actions has yet 
to be elucidated. A weak estrogenic action for BPA was confirmed by an approximately $1 / 15,000$ lower affinity for ER $\alpha$ than E2, endogenous estrogen, estimated using a yeast-based steroid hormone receptor gene transcription assay [7]. When pregnant mice orally received a low-dose of BPA (2.4 $\mu \mathrm{g} / \mathrm{kg} / \mathrm{day}$; equal dose to environmental exposure [8]) during the organogenic period, the span of the vaginal opening and first vaginal estrus in female offspring was significantly reduced [9]. To evaluate the effects of BPA on embryonic development, we previously determined the mRNA levels of retinoid receptors [retinoic acid receptor $\alpha(R A R \alpha ; N R 1 A B)$ and retinoid $X$ receptor- $\alpha(\mathrm{RXR} \alpha ; \mathrm{NR} 2 \mathrm{~B} 1)]$ in murine embryos that were exposed in utero to BPA $(0.02,2,200$, and $20,000 \mu \mathrm{g} / \mathrm{kg} /$ day) at $6.5-17.5$ days post-coitum $(\mathrm{dpc})$ using the quantitative real-time reverse transcription-polymerase chain reaction (RT-PCR) method, and confirmed the following [10]: RAR $\alpha$ and RXR $\alpha$ mRNAs were expressed in the cerebra, cerebella, and gonads (testes and ovaries) of male and female murine embryos from 12.5 to $18.5 \mathrm{dpc}$. Exposure to BPA in utero disrupted the expression of RAR $\alpha$ and RXR $\alpha$ mRNAs in cerebra and cerebella of male and female embryos. Interestingly, an extremely low dose of BPA (0.02 $\mu \mathrm{g} / \mathrm{kg} / \mathrm{day} ; 1 / 100$ the level received from environmental exposure) significantly increased RAR $\alpha$ mRNA expression in the cerebella of male and female 14.5- and 18.5-dpc-embryos and in the gonads of female 14.5-dpc-embryos, and significantly increased RXR $\alpha$ mRNA expression in the cerebra and cerebella of male and female 14.5dpc-embryos. These results indicate that exposure to a low dose of BPA in utero affects the levels of RAR $\alpha$ and RXR $\alpha$ mRNAs in murine embryos, and BPA disrupts sex differentiation and gonadal development by disrupting the expression of RAR $\alpha$ and $R X R \alpha$.

The aryl hydrocarbon receptor (AhR) mediates the toxicological effects of polycyclic aromatic hydrocarbons (PAHs), a family of toxic compounds that includes 2,3,7,8-tetrachlorodibenzo- $p$-dioxin (TCDD), polychlorinated biphenyls, and polycyclic aromatic hydrocarbons [11-18]. The major toxic effects of PAHs, mainly TCDD, are mediated by AhR, which has high binding affinity for PAHs. In the absence of a ligand, AhR exists in a cytoplasmic complex with 3 partner molecules [heat shock protein 90 (Hsp90), co-chaperon p23, and immunophilin-like protein XAP2/AIP / ARA9]. When ligand/compound binds with AhR, ligandAhR replaces its partner Hsp90-p23-XAP2-complex with the AhR nuclear translocator (Arnt), and then translocates into the nucleus. In the nucleus, the AhR-Arnt heterodimeric complex binds with a specific DNA sequence designated XRE/DRE/ AhRE (the core consensus sequence is $5^{\prime}$-TNG CGT G-3') in the promoter region of target genes, and enhances the transcription of these genes. Some of the target genes encode xenobiotic metabolizing enzymes [XMEs; cytochrome P450 1A1 (CYP1A1: a typical XME induced by PAHs9), CYP1A2, CYP1B1, UDP-glucuronosyltransferase, the glutathione $S$-transferase Ya subunit (GST), quinone oxidoreductase, nicotinamide adenine dinucleotide phosphate-oxidoreductase, and so on] $[19,20]$. Aryl hydrocarbon receptor repressor (AhRR), which dimerizes with Arnt protein and competes with AhR to bind XRE, is also induced by the AhR-Arnt heterodimeric complex, plays a key role in the negative feedback mechanism, and down-regulates the AhR-mediated gene expression [21]. It remains to be elucidated how AhR is involved in TCDD-induced toxicobiological effects, such as teratogenesis and immunsuppression. It is considered that the toxic effects of TCDD are caused by the expression of specific genes induced by ligand-binding/activated AhR. AhR-knockout (KO) mice were resistant to the acute toxicity of TCDD, but had an alternated teratogenic response to TCDD [22-24]. The embryos and adults had a number of abnormal phenotypes and were defective in the development of liver and immune systems. AhR-KO mice showed vitamin A/retinoid accumulation in the liver and an abnormal morphology in the liver and kidneys, thus confirming that AhR plays important roles in embryonic morphogenesis. Among the most consistent phenotypes of AhR-KO mice, an abnormal vascular structure in the liver is considered to be associated with accelerated rates of hepatocyte apoptosis. Pathogenic findings suggested that accelerated rates of apoptosis may be related to an abnormal accumulation of retinoic acid in hepatocytes, and such an accumulation causes a hyper-activation of transforming growth factor- $\beta 1$, resulting in higher rates of hepatocyte apoptosis [24].

In the preimplantation embryos of normal mice, the mRNA and protein of AhR, which regulates the 
levels of CYPs responsible for the metabolism of retinoic acid, were detected and had marked effects on embryogenesis (cell proliferation, growth, differentiation, and death) [25-28]. The oxidative conversion of all-trans-retinol $(t-\mathrm{ROH})$ to $t$-retinal ( $t$-RAL) is the rate-limiting step in the biosynthesis of $t$-RA from $t$-ROH in mammalian tissues [26]. CYP1A1 and CYP1B1 play important roles in the biosynthesis of $t$-RA from $t$-ROH. CYP1A2 and CYP3A4 are the major cytochrome P450 enzymes catalyzing the oxidative conversion of $t-\mathrm{ROH}$ to $t$ RAL. In addition, CYP1A1, UDP-glucuronosyltransferase, and GST play crucial roles in the metabolism of xenobiotic compounds. In adult rats, approximately $60 \%$ of orally ingested BPA was rapidly absorbed by the small intestine, transfered to the liver, and metabolized by enzymes such as CYP1A1, UDP-glucuronosyltransferase, and GST, within $60 \mathrm{~min}[29,30]$. However, UDP-glucuronosyltransferase and GST levels were extremely low, and the activity levels of these enzymes, which were assessed biochemically using xenoestrogens as a substrate, were increased during growth in neonatal rats [31]. Thus, AhR is not only a key receptor in xenobiotic metabolism but also a crucial receptor mediating embryogenesis and teratogenesis. AhR protein is expressed in most organs of adult mice $[32,33]$ and in the livers of murine embryos at 9.5-dpc [34, 35]. However, the changes in the expression of AhR mRNA in murine embryos during embryogenesis have yet to be demonstrated. In the present study, to evaluate the effects of BPA on metabolism of xenobiotic compounds in murine embryos (from mid- to latestages), we examined the mRNA levels of AhR, AhRR, Arnt, CYP1A1, and GST in the cerebra, cerebella, and gonads of murine embryos using the quantitative real-time reverse transcriptionpolymerase chain reaction (RT-PCR) technique. In addition, changes in the protein levels of CYP1A1 and GST in embryonic livers were examined by Western immunoblotting.

\section{Materials and Methods}

\section{Preparation of embryonic tissue}

Male and female ICR mice (Clea Japan, Tokyo, Japan) were housed under controlled temperature (24 $\pm 2 \mathrm{C})$, lighting (12 h light: $12 \mathrm{~h}$ darkness), and humidity $(75 \pm 5 \%)$, and given a standard diet (CM;
Oriental Yeast, Tokyo, Japan) and tap water ad libitum. They received humane care as outlined in the "Guide for the Care and Use of Laboratory Animals" (Kyoto University Animal Care Committee according to NIH No. 86-23; revised 1999). After mating, females found to have a vaginal plug were considered to be at $0.5 \mathrm{dpc}$. To determine the effects of BPA (Wako Pure Chemicals, Osaka, Japan), pregnant mice were orally administered BPA $(0.02,2,200$, or 20,000 $\mu \mathrm{g} /$ $\mathrm{kg} /$ day; dissolved in olive oil) and E2 (5 $\mu \mathrm{g} / \mathrm{kg} /$ day dissolved in olive oil; Wako). These doses were based on our previous studies [12,36,37]. The oral administration was performed in the afternoon (12:00 to $14: 00$ ) from 6.5 to 13.5 , and 6.5 to $17.5 \mathrm{dpc}$ (8 and 12 times, respectively). Vehicle controls were orally treated with purified olive oil $(5 \mathrm{ml} / \mathrm{kg})$ under the same conditions. Pregnant mice were sacrificed at 14.5 and $18.5 \mathrm{dpc}(\mathrm{n}=12$ /each group) under anesthesia with diethyl ether (Wako) $24 \mathrm{~h}$ after the last administration of BPA. The embryos were rapidly removed, weighed, and dissected. For quantitative real-time RT-PCR and Western immunoblot analysis, the cerebrum, cerebellum, gonads (ovaries and testes), and liver of male and female embryos were frozen and kept in liquid nitrogen prior to use.

\section{Quantitative real-time RT-PCR analysis}

Quantitative real-time RT-PCR analysis was performed according to our previous reports [12, 37, 38]. Briefly, total RNA was extracted from each embryonic organ using a RNeasy Mini Kit (Qiagen, Valencia, CA, U.S.A.), and then $1 \mu \mathrm{g}$ /organ of the total RNA was reverse-transcribed with an oligo(dT) primer using a T-primed First-Strand Kit (Amersham Pharmacia Biotech, Piscataway, NJ, U.S.A.) to synthesize the first strand cDNA. The cDNA was quick-chilled on ice to denature the RNA-cDNA duplex. mRNA levels of AhR, RAR $\alpha$, $\mathrm{RXR} \alpha$, and glyceraldehydes-3-phosphate dehydrogenase (GAPDH; used as an intrinsic control) were quantified using a LightCycler System (Roche Diagnostics, Rotkreuz, Switzerland), according to the manufacturer's instructions. PCRs were performed in $20 \mu \mathrm{l}$ of a reaction mixture (Light-Cycler-DNA Master SYBR Green I; Roche) containing $0.5 \mu \mathrm{M}$ of each primer, nucleotides, Taq DNA polymerase, and $3 \mathrm{mM}$ $\mathrm{MgCl}_{2}$. Primers for the amplification of partial cDNA sequences of AhR, Arnt, AhRR, CYP1A1, 
GST, and GAPDH were as follows: AhR forward: 5'-AGCAT CATGA GGAAC CTTGG-3', reverse: 5' GGATT TCGTC CGTTA TGTCG-3'; Arnt forward: 5'-GGTTC GGGAG CACAC TGTAT-3', reverse: 5'CCTTC CTTCA CAGAG CCAAG-3'; AhRR forward: 5'CTGCC CAGGT ACTCT GAACC-3', reverse: 5'-AGTGT CCACA AAGCC TGACC-3'; CYP1A1 forward: 5'-GGCCA CTTTG ACCCT TACAA-3', reverse: 5'-CAGGT AACGG AGGAC AGGAA-3'; GST forward: 5'-TTCCA TCCCT GAGAC ACCTC-3', reverse: 5'-CCCAT ACAGA CAAGT GGGCT-3'; and GAPDH forward: 5'GGGTG GAGCC AAACG GGTC-3', reverse: 5' GGAGT TGCTG TTGAA GTCGC A-3'. Additionally, to determine the sex of each embryo, genomic DNA samples were prepared from the liver using a Miniprep Kit (Qiagen), and then PCR for the Y chromosome Sry gene was performed according to McClive and Sinclair [39]. The Sry gene in each sample was amplified using the following primer pair: forward: 5'-TCATG AGACT GCCAA CCACA G-3', and reverse: 5'-CATGA CCACC ACCAC CACCA A-3'. The hot-start PCR profile was as follows: $95 \mathrm{C}$ for $10 \mathrm{~min}$, then 45 cycles of $95 \mathrm{C}$ for $15 \mathrm{sec}, 57 \mathrm{C}$ for $5 \mathrm{sec}, 72 \mathrm{C}$ for $8 \mathrm{sec}$, and a final extension at $62 \mathrm{C}$ for $10 \mathrm{sec}$. Quantification was performed using Light-Cycler analysis software (Roche) on an IBM compatible computer (Hewlett-Packard, Palo Alto, CA, U.S.A.). The relative abundance of specific mRNA was normalized to the relative abundance of GAPDH mRNA. The DNA sequence of each PCR product was determined with an automatic DNA sequencer (ABI Prism 310; PE Applied Biosystems, Foster City, CA, U.S.A.) according to the manufacturer's directions, and then the expression of AhR, Arnt, AhRR, CYP1A1, and GST mRNAs was confirmed.

\section{Western immunoblotting}

Each frozen liver sample prepared from an embryo was homogenized in PBS containing a protease inhibitor mixture (Sigma-Aldrich Co., St. Louis, MO, U.S.A.). The protein concentration in each sample was measured using a Bradford Detection Kit (Bio-Rad Laboratories, Hercules, CA, U.S.A.). Equal amounts of protein (50 $\mu \mathrm{g} /$ lane) were separated on 5-20\% gradient SDS-PAGE gels (Bio-Rad), and then transferred to nitrocellulose membranes (Invitrogen, Carlsbad, CA, U.S.A.). Western immunoblotting was performed using primary antibodies [rabbit polyclonal anti-CYP1A1 and GST antibodies (1:500; Dako, Glostrup, Denmark)] and secondary antibody [horse radish peroxidase (HRP)-conjugated goat anti-rabbit IgG antibody $(1: 2,000 ;$ Dako)], which was used to identify where the primary antibody bound. The chemi-luminescence was visualized using an enhanced chemiluminescence system (Amersham Pharmacia Biosciences) according to the manufacturer's protocols, and recorded with a digital fluorescene recorder (LAS-1000; Fuji Film, Tokyo, Japan). The intensity of chemiluminescence was quantified using the ImageGauge software (Fuji Film) on a Macintosh computer (Apple, Cupertino, CA, U.S.A.).

\section{Statistical analysis}

ANOVA for the real-time RT-PCR and Western immunoblot data was carried out using the StatView-4.5 program (Abcam, Cambridge, UK) on a Macintosh computer. Differences of $P<0.05$ were considered significant.

\section{Results}

Changes in levels of AhR mRNA in embryonic organs

We summarized the effects of exposure to BPA in utero on the expression levels of AhR mRNA in the cerebra (Fig. 1A and B), cerebella (Fig. 1C and D), and gonads (testes and ovaries; Fig. $1 \mathrm{E}$ and $\mathrm{F}$ ) of 14.5- (Fig. 1A, C, and E) and 18.5-dpc-embryos (Fig. $1 B, D$, and F). The exposure remarkably increased AhR mRNA expression in the cerebra, cerebella, and gonads of both male and female 14.5- and 18.5dpc-embryos. Interestingly, an extremely low dose of BPA $(0.02 \mu \mathrm{g} / \mathrm{kg} /$ day; which is less than $1 / 100$ the dose received from environmental exposure) had strong effects on the levels of AhR mRNA as follows: In the cerebra of male and female embryos at $14.5 \mathrm{dpc}$, exposure to BPA up-regulated the AhR mRNA expression (Fig. 1A). In the cerebra of 18.5dpc-embryos (Fig. 1B), BPA (0.02, 200, and 20,000 $\mu \mathrm{g} / \mathrm{kg} /$ day) markedly increased the levels of AhR mRNA (more than 50-fold; $P<0.001$ ). In the cerebella of 14.5- and 18.5-dpc-embryos (Fig. 1C and $D$, respectively), exposure to extremely low (0.02 $\mu \mathrm{g} / \mathrm{kg} /$ day) and high (200 and 20,000 $\mu \mathrm{g} / \mathrm{kg} /$ day, respectively) doses of BPA up-regulated the expression of AhR mRNA (40- to 80-fold; $P<0.01$ and 0.001 ). In the gonads of 14.5-dpc-embryos (Fig. 


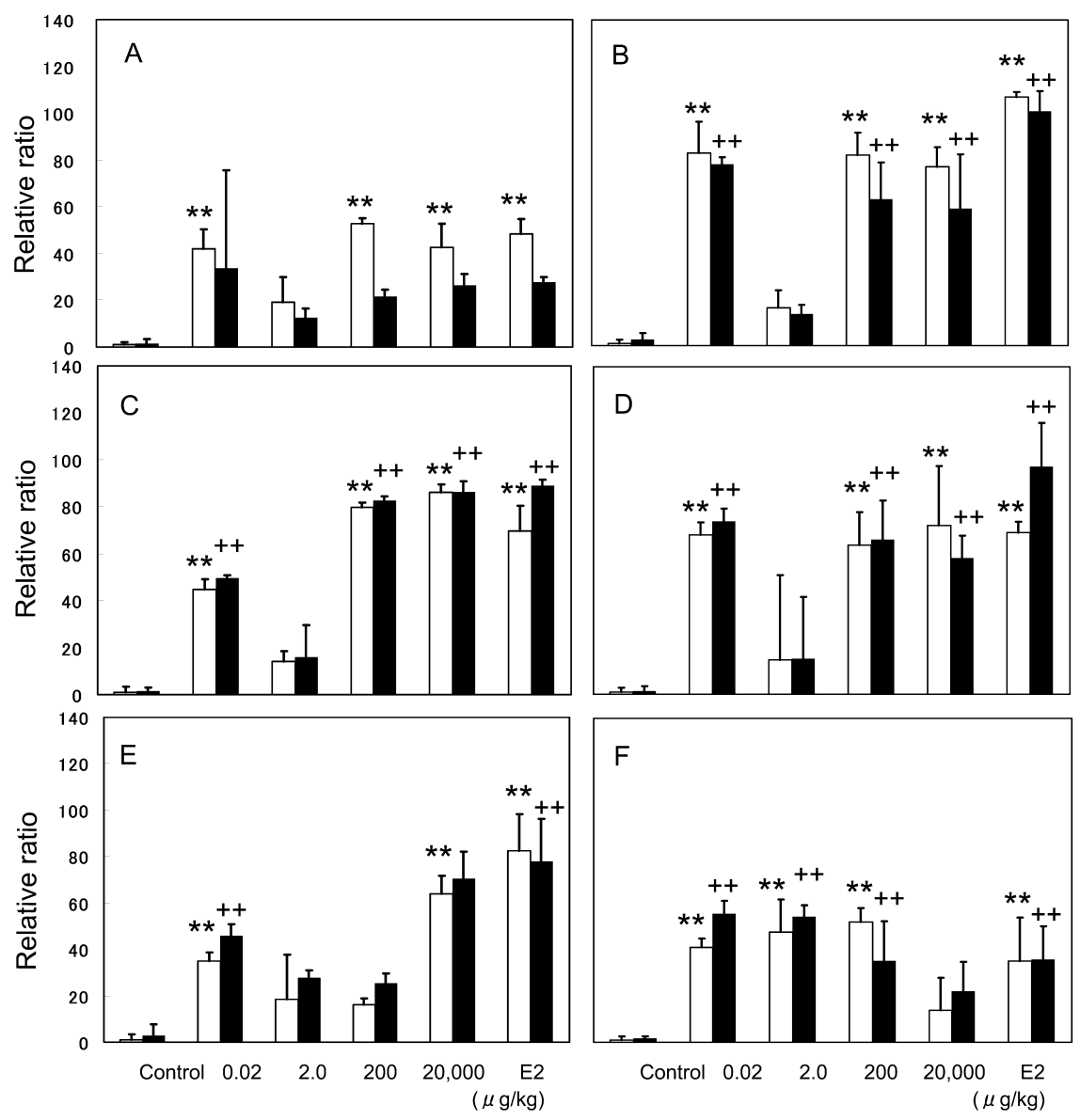

Fig. 1. Changes in levels of AhR mRNA in the cerebra (A and B), cerebella (C and D), and gonads (testes and ovaries: $\mathrm{E}$ and F) of 14.5- (A, C, and E) and 18.5-dpc-embryos (B, D, and F). Open and closed bars represent males and females, respectively. In $\mathrm{E}$ and $\mathrm{F}$, open and closed bars represent testes and ovaries, respectively. Each value is the mean \pm SEM. ${ }^{* *}$ and ${ }^{* * *}: P<0.01$ and 0.001 , respectively, vs each male vehicle control. ${ }^{+++}$, and ${ }^{+++}: P<0.05,0.01$, and 0.001 , respectively, vs each female vehicle control.

1E), exposure to extremely low- and high-doses of BPA $(0.02$ and $20,000 \mu \mathrm{g} / \mathrm{kg} /$ day, respectively) markedly increased the AhR mRNA expression (more than 30- and 70-fold; $P<0.01$ and 0.001), and 2 and $200 \mu \mathrm{g} / \mathrm{kg} /$ day of BPA also increased the expression. AhR mRNA expression showed a diphasic (U) dose-response curve following exposure to BPA. In the gonads of 18.5 -dpcembryos (Fig. 1F), exposure to BPA, except at $20,000 \mu \mathrm{g} / \mathrm{kg} /$ day, increased the expression levels of AhR mRNA $(P<0.01)$.

\section{Changes in levels of AhRR mRNA in embryonic organs}

In Fig. 2, we summarized the effects of exposure to BPA in utero on the expression of AhR mRNA in the cerebra (Fig. 2A and B), cerebella (Fig. 2C and $\mathrm{D}$ ), and gonads (testes and ovaries; Fig. 2E and F) of 14.5- (Fig. 2; A, C, and E) and 18.5-dpc-embryos (Fig. 2B, D, and F). In the cerebra and cerebella of male and female 14.5- and 18.5-dpc-embryos, an extremely low dose of BPA $(0.02 \mu \mathrm{g} / \mathrm{kg} /$ day $)$ had a strong up-regulating effect on the expression of AhRR mRNA. In the cerebra and cerebella of male and female 14.5 -dpc embryos, $0.02 \mu \mathrm{g} / \mathrm{kg} /$ day significantly increased the levels of AhRR mRNA and this increase was larger than in higher doses of BPA (200 and 20,000 $\mu \mathrm{g} / \mathrm{kg} /$ day $)(P<0.05$ and 0.01$)$. At $18.5 \mathrm{dpc}$ (Fig. 2B and D), extremely low and high doses of BPA $(0.02$ and 20,000 $\mu \mathrm{g} / \mathrm{kg} / \mathrm{day}$, 

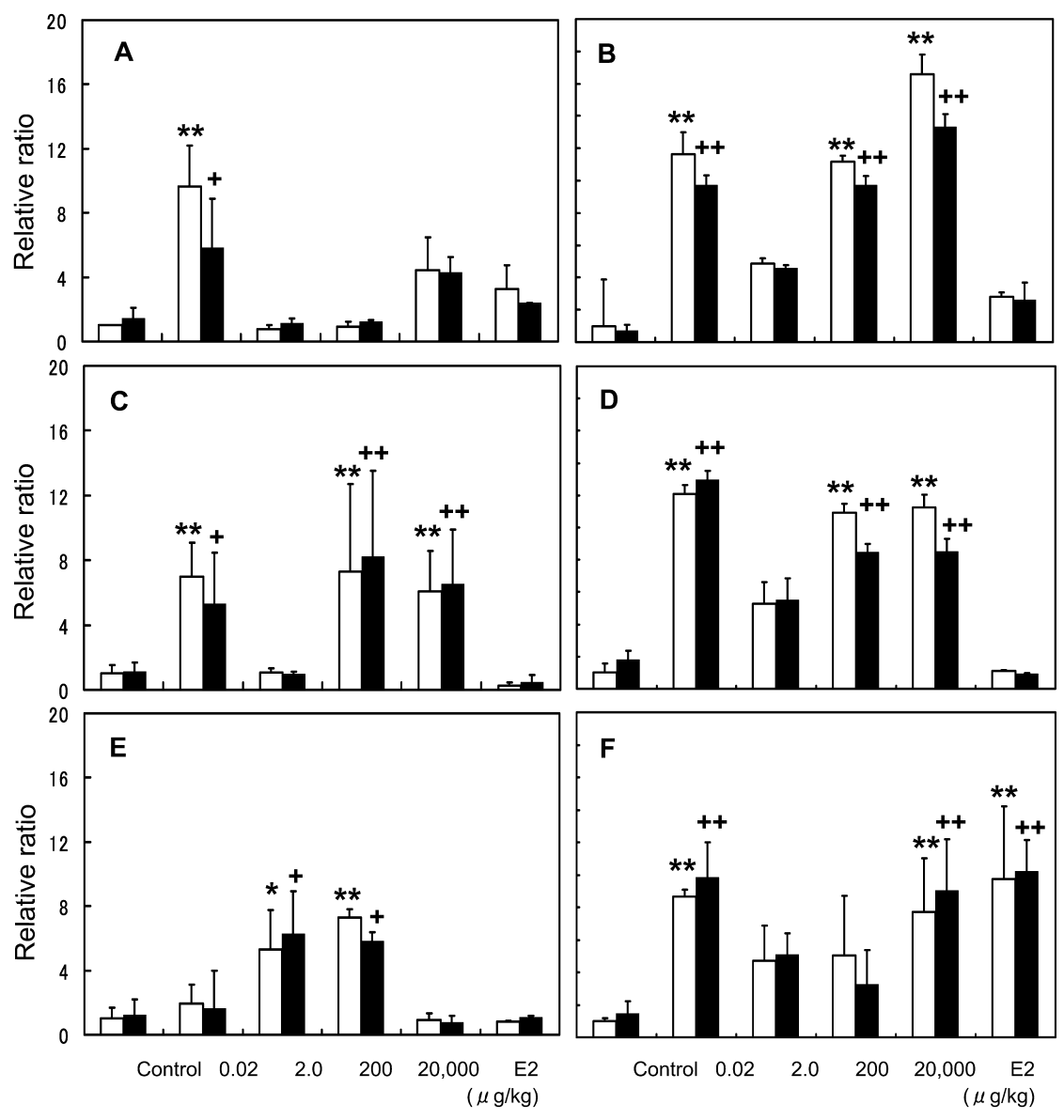

Fig. 2. Changes in levels of AhRR mRNA in the cerebra (A and B), cerebella (C and D), and gonads (testes and ovaries: $\mathrm{E}$ and $\mathrm{F}$ ) of 14.5- (A, C, and E) and 18.5-dpcembryos (B, D, and F). Open and closed bars represent males and females, respectively. In $\mathrm{E}$ and $\mathrm{F}$, open and closed bars represent testes and ovaries, respectively. Each value is the mean \pm SEM. ${ }^{* *}$ and ${ }^{* *}: P<0.01$ and 0.001 , respectively, vs each male vehicle control. ${ }^{+,++}$, and ${ }^{++}: P<0.05,0.01$, and 0.001 , respectively, vs each female vehicle control.

respectively) significantly up-regulated the expression of AhRR mRNA $(P<0.01$ and 0.001 , respectively). In the cerebra and cerebella of $14.5-$ and 18.5-dpc-embryos, however, E2 had no remarkable effect. At $18.5 \mathrm{dpc}$, extremely low- and high-doses of BPA $(0.02$ and $20,000 \mu \mathrm{g} / \mathrm{kg} /$ day $)$ and E2 up-regulated the expression of AhRR mRNA (more than 10 -fold; $P<0.01$ or 0.001 ).

\section{Changes in levels of Arnt mRNA in embryonic} organs

The effects of exposure to BPA in utero on the expression of AhR mRNA in the cerebra (Fig. 3A and B), cerebella (Fig. 3C and D), and gonads (testes and ovaries; Fig. 3E and F) of 14.5- (Fig. 3A, C, and
E) and 18.5-dpc-embryos (Fig. 3B, D, and F) are summarized in Fig. 3. In the cerebra and cerebella of male and female 14.5- and 18.5-dpc-embryos, BPA, except at $2 \mu \mathrm{g} / \mathrm{kg} /$ day, increased the level of Arnt mRNA. BPA and E2 had no effect in gonads of 14.5-dpc-embryos (Fig. 3E), but an extremely low dose of BPA $(0.02 \mu \mathrm{g} / \mathrm{kg} /$ day $)$ markedly upregulated the expression of Arnt mRNA in the gonads of 18.5-dpc-embryos (Fig. 3F; $P<0.05$ and $0.01)$.

Changes in levels of CYP1A1 mRNA in embryonic organs

The effects of exposure to BPA in utero on the expression of CYP1A1 mRNA in the cerebra (Fig. 


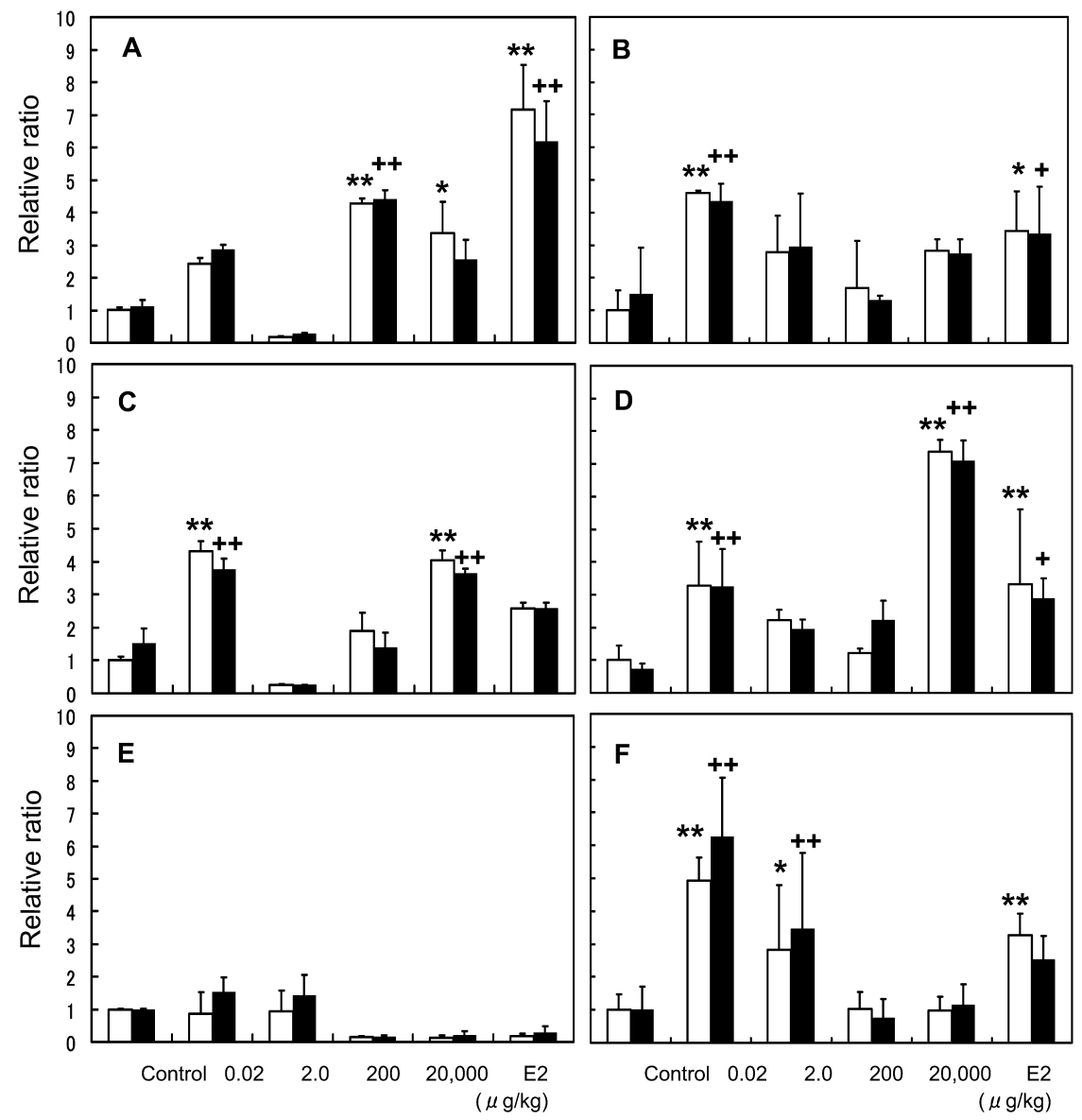

Fig. 3. Changes in levels of Arnt mRNA in the cerebra (A and B), cerebella (C and D), and gonads (testes and ovaries: $\mathrm{E}$ and $\mathrm{F}$ ) of 14.5- (A, C, and E) and 18.5-dpcembryos (B, D, and F). Open and closed bars represent males and females, respectively. In E and F, open and closed bars represent testes and ovaries, respectively. Each value is the mean \pm SEM. ${ }^{* *}$ and ${ }^{* * *}: P<0.01$ and 0.001 , respectively, vs each male vehicle control. ${ }^{+,+}$, and ${ }^{+++}: P<0.05,0.01$, and 0.001 , respectively, vs each female vehicle control.

$4 \mathrm{~A}$ and $\mathrm{B}$ ), cerebella (Fig. $4 \mathrm{C}$ and $\mathrm{D})$, and gonads (testes and ovaries; Fig. 4E and F) of 14.5- (Fig. 4A, C, and E) and 18.5-dpc-embryos (Fig. 4B, D, and F) are summarized in Fig. 4. In all tissues of control male and female 14.5- and 18.5-dpc-embryos, only trace levels of CYP1A1 mRNA expression were detected. In the cerebra and cerebella of 18.5-dpcembryos (Fig. 4B and D), BPA dose-dependently up-regulated the expression of CYP1A1 mRNA.

\section{Changes in levels of GST mRNA in embryonic organs}

The effects of exposure to BPA in utero on the expression of GST mRNA in the cerebra (Fig. 5A and B), cerebella (Fig. 5C and D), and gonads (testes and ovaries; Fig. 5E and F) of 14.5- (Fig. 5A, C, and E) and 18.5-dpc-embryos (Fig. 5B, D, and F) are summarized in Fig. 5. In all tissues of control male and female 14.5- and 18.5-dpc-embryos, only trace levels of GST mRNA were detected. In the cerebra and cerebella of 14.5-dpc-embryos (Fig. 5A and C), E2 increased the expression of GST mRNA $(P<0.05)$. In the cerebra and cerebella of 18.5 -dpcembryos (Fig. 5B and D), BPA dose-dependently increased the GST mRNA levels. In the gonads of 18.5-dpc-embryos (Fig. 5F), BPA (200 and 20,000 $\mu \mathrm{g} / \mathrm{kg} /$ day) and E2 remarkably increased the expression $(P<0.01)$. 

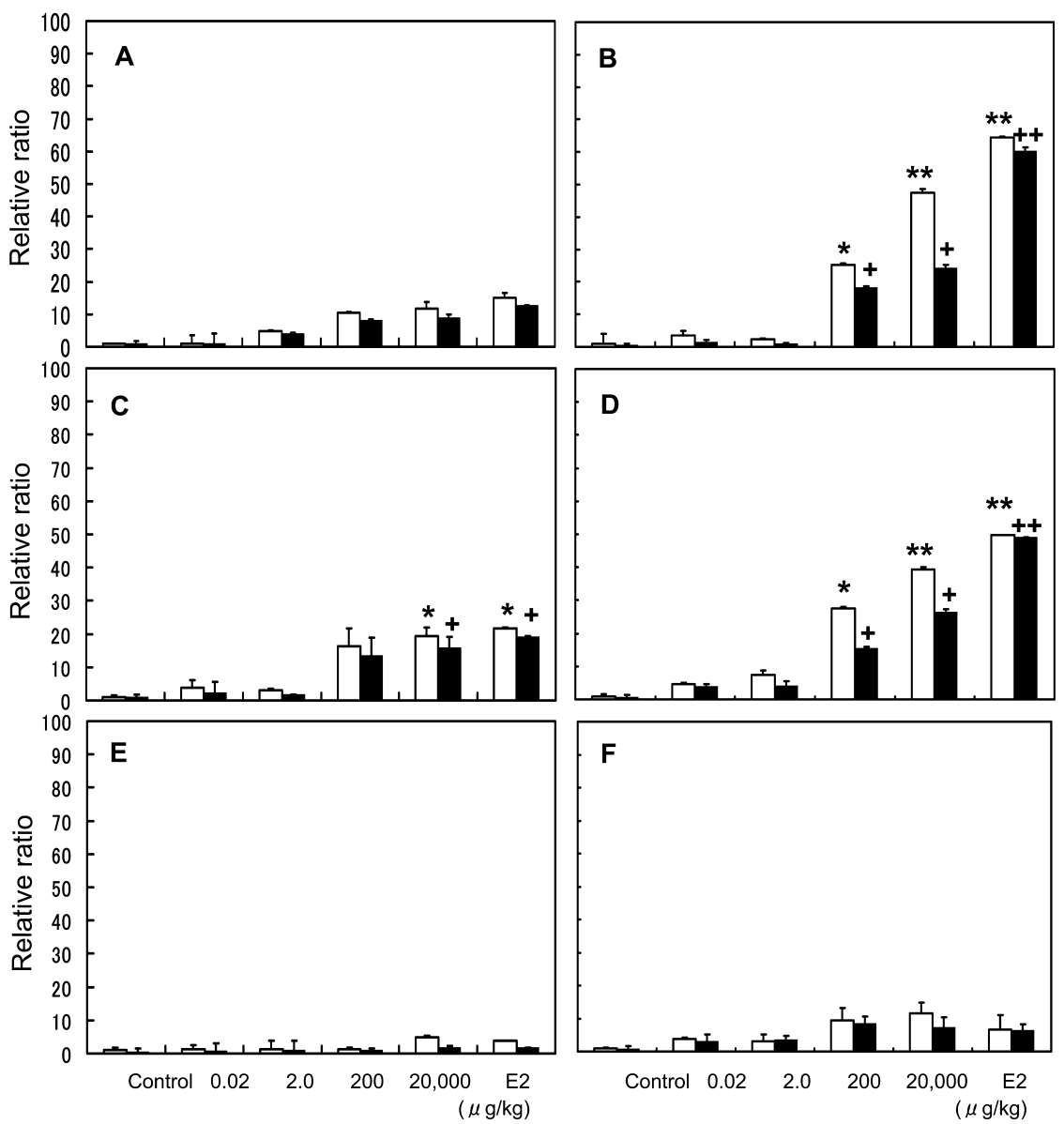

Fig. 4. Changes in levels of CYP1A1 mRNA in the cerebra (A and B), cerebella (C and D), and gonads (testes and ovaries: $\mathrm{E}$ and F) of 14.5- (A, C, and E) and 18.5-dpcembryos (B, D, and F). Open and closed bars represent males and females, respectively. In $\mathrm{E}$ and $\mathrm{F}$, open and closed bars represent testes and ovaries, respectively. Each value is the mean \pm SEM. ${ }^{* *}$ and ${ }^{* *}: P<0.01$ and 0.001 , respectively, vs each male vehicle control. ${ }^{+,+}{ }^{+}$and ${ }^{+++}: P<0.05,0.01$, and 0.001 , respectively, vs each female vehicle control.

Changes in protein levels of CYP1A1 and GST in embryonic livers

The effects of exposure to BPA in utero on the protein levels of CYP1A1 and GST in the livers of 18.5-dpc-embryos are summarized in Fig. 6. An extremely low dose of BPA $(0.02 \mu \mathrm{g} / \mathrm{kg} /$ day $)$ had no effect on the protein level of CYP1A1 or GST, but higher doses ( 2 and $200 \mu \mathrm{g} / \mathrm{kg} /$ day) of BPA increased both levels $(P<0.05)$. An extremely high dose of BPA $(20,000 \mu \mathrm{g} / \mathrm{kg} /$ day) and E2 markedly enhanced the levels $(P<0.01)$. In the livers of 14.5 dpc-embryos, these proteins were not detectable by Western immunoblotting (data not shown).

\section{Discussion}

BPA exhibits an estrogenic activity by binding to estrogen and/or androgen receptor(s) [5-8]. A weak estrogenic action of BPA was confirmed by an approximately $1 / 15,000$ lower affinity for ER $\alpha$ than E2 [9]. When pregnant mice received BPA $(2.4 \mu \mathrm{g} /$ $\mathrm{kg} /$ day), sexual maturation in female offspring significantly decreased [11]. An in vitro study [40] using early-stage embryos of mice showed that BPA (at concentrations of 1 and $3 \mathrm{nM}$ ) had stimulatory effects on blastocyst formation, but 100 $\mu \mathrm{M}$ BPA was inhibitory, indicating BPA has bifocal effects on embryogenesis. In adult ovariectomized rats, oral administration of BPA $(100-10,000 \mu \mathrm{g} /$ 


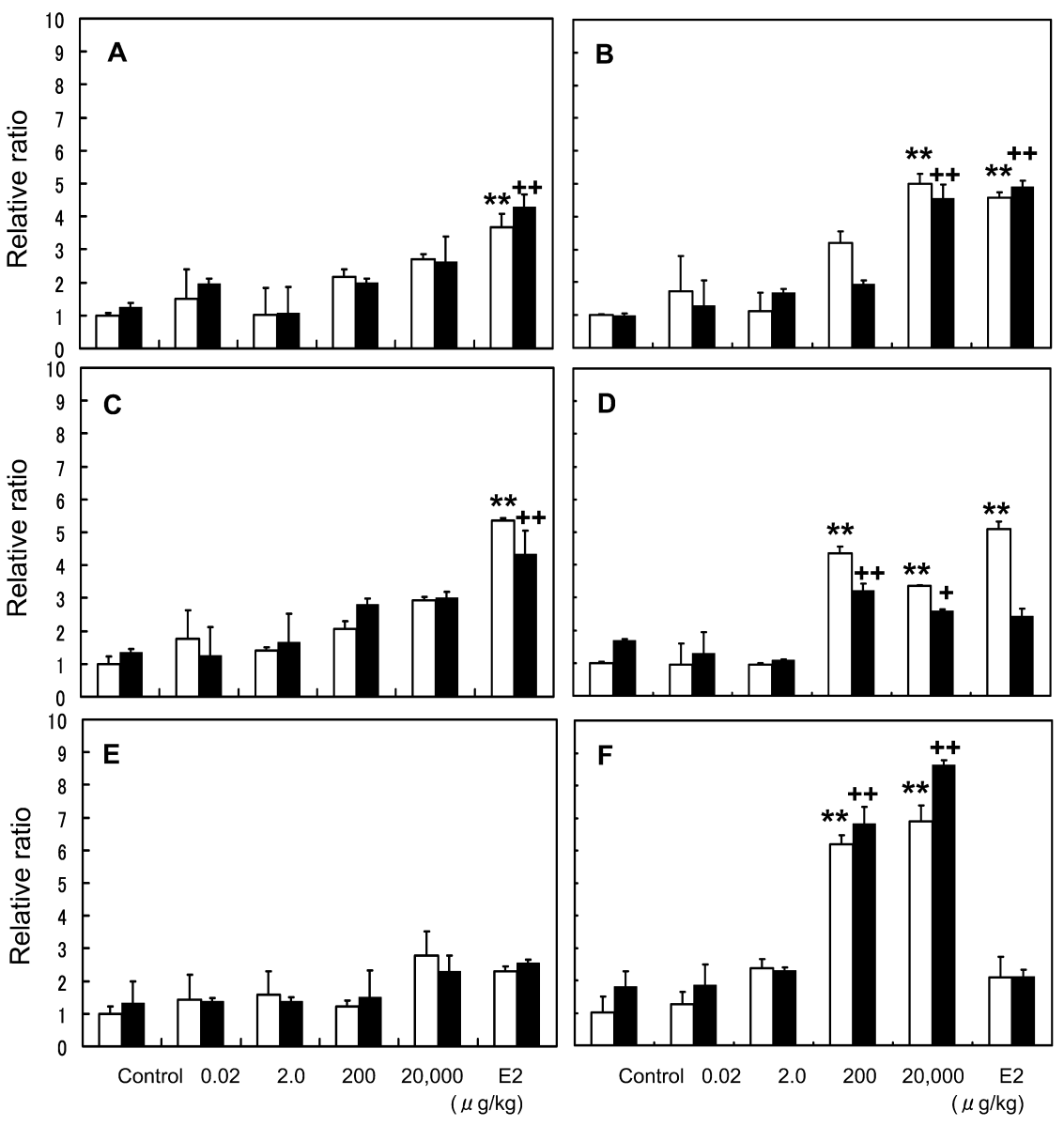

Fig. 5. Changes in levels of GST mRNA in the cerebra (A and B), cerebella (C and D), and gonads (testes and ovaries: $\mathrm{E}$ and $\mathrm{F}$ ) of 14.5- (A, C, and $\mathrm{E}$ ) and 18.5-dpc-embryos $(\mathrm{B}, \mathrm{D}$, and F). Open and closed bars represent males and females, respectively. In $\mathrm{E}$ and $\mathrm{F}$, open and closed bars represent testes and ovaries, respectively. Each value is the mean \pm SEM. ${ }^{* *}$ and ${ }^{* * *}: P<0.01$ and 0.001 , respectively, vs each male vehicle control. ${ }^{+++}$, and ${ }^{++}: P<0.05,0.01$, and 0.001 , respectively, vs each female vehicle control.

$\mathrm{kg} /$ day) dose-dependently increased the expression of the progesterone receptor in hypothalamus cells and affected sexual behavior [41]. Because the effects of exposure to BPA ( $2 \mu \mathrm{g} /$ $\mathrm{kg} /$ day) in utero on embryonic development have not been reported yet, we previously showed that higher mRNA levels of RAR $\alpha$ and RXR $\alpha$, factors essential for embryogenesis in mammals [27, 28, 42-44], were detected in the cerebra and cerebella of murine embryos at $12.5,14.5,16.5$, and $18.5 \mathrm{dpc}$ by a quantitative real-time RT-PCR method. An extremely low dose of BPA $(0.02 \mu \mathrm{g} / \mathrm{kg} /$ day $)$ significantly increased levels of RAR $\alpha$ mRA in the cerebella of male and female 14.5- and 18.5-dpcembryos and in the ovaries of 14.5-dpc-embryos
[12]. The mRNA levels of RAR $\alpha$ and $R X R \alpha$ are sensitive parameters with which to assess the toxic effects of BPA on embryogenesis. The classical endocrine disrupting mechanism of BPA is considered to be as follows: BPA acts as an antagonist of estrogen and binds with ERs. In this paper, we propose a novel endocrine disrupting mechanism, whereby BPA up-regulates the mRNA expression of AhR.

AhR binds with xenobiotic compounds, such as TCDD, and then mediates their toxic effects [16]. Moreover, AhR acts as an inducer of XMEs, and so enhances the metabolism of xenobiotic compounds $[29,30]$. To date, the effects of BPA on the metabolism of xenobiotic compounds mediated by 

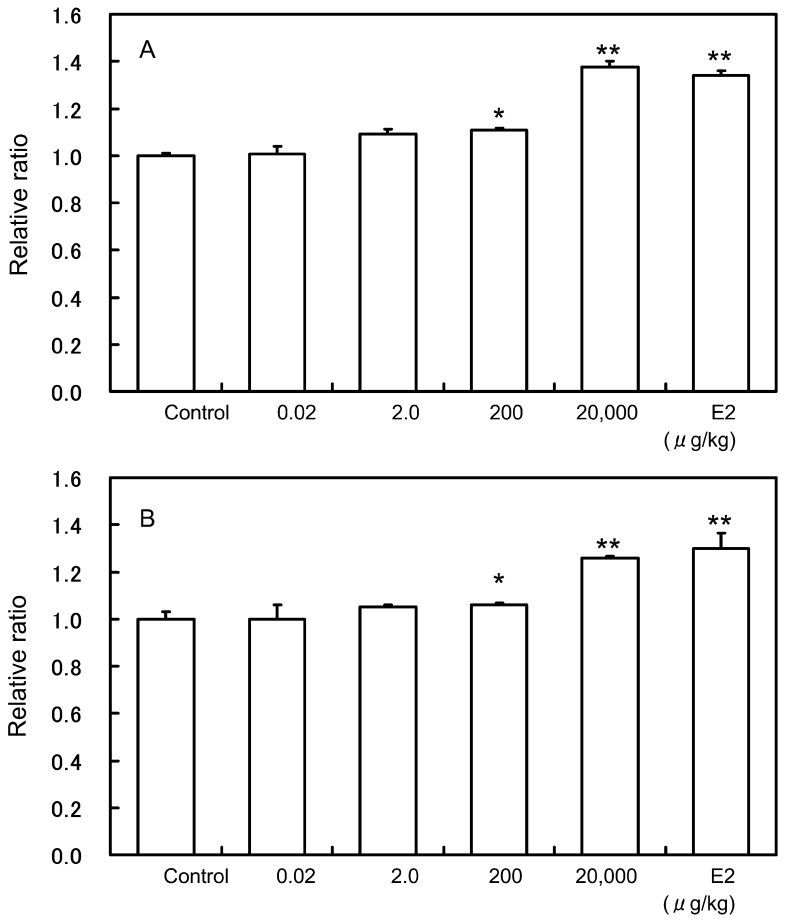

Fig. 6. Changes in protein levels of CYP1A1 and GST in the livers (A and B, respectively) of 18.5-dpc-embryos. Each value is the mean \pm SEM. ${ }^{*}$ and ${ }^{* *}: P<0.05$ and 0.01 , respectively, vs each control.

AhR during the development of mammalian embryos have not been reported. Furthermore, detailed studies on the expression patterns of AhR and related factors, on XMEs during embryogenesis, and on the effects of exposure to BPA in utero on the expression levels of these factors have not been conducted. In the present study, to determine the effects of BPA on the metabolism of xenobiotic compounds, we examined the expression patterns of $A h R$ and related factors, and of XMEs in murine embryos exposed to BPA in utero. We demonstrated that the exposure up-regulated the expression of AhR, AhRR, Arnt, CYP1A1, and GST mRNAs in the cerebra, cerebella, and gonads of male and female 14.5- and 18.5-dpc-embryos. In all tissues of 14.5and 18.5-dpc-embryos, BPA dose-independently increased the AhR mRNA levels. Interestingly, an extremely low dose of BPA $(0.02 \mu \mathrm{g} / \mathrm{kg} /$ day $)$ remarkably increased the expression of AhR mRNA in the cerebra, cerebella, and gonads of male and female 14.5- and 18.5-dpc-embryos. In the same low dose treatment group, high levels of
AhRR and Arnt mRNAs were also noted. BPA upregulated the mRNA expression of XMEs (CYP1A1 and GST) in the cerebra, cerebella, and gonads of the mid-developmental stage (14.5-dpc) embryos, but had no effect on the late-developmental stage (18.5-dpc) embryos. However, protein levels of these enzymes in the livers of 14.5-dpc-embryos were extremely low (not detectable by Western immunoblotting), and BPA increased the expression of these enzymes in 18.5-dpc-embryos. These findings indicate that a low dose of BPA (less than or equal to environmental levels of exposure) can disrupt the AhR-mediated metabolism of xenobiotic compounds in embryonic organs, but BPA has no effect on the protein levels of XMEs in the livers of embryos. Because metabolic enzyme levels in embryonic livers are extremely low, BPA may accumulate in the organs of mid-stage embryos. These metabolic enzymes are catalyzers for the metabolites of exogenous and endogenous estrogen(s) [45], and so we speculate that BPA disrupts the estrogen-dependent signal transducing system not only via the direct interruption of ER expression [46, 47], but also through the indirect disruption of estrogen catabolic-metabolism.

The AhR/Arnt heterodimer directly associates with ERs and estrogen-responsive gene promoters are activated [48]. Such activation up-regulates the transcription and enhances the estrogenic effects. BPA increased the expression of both AhR and Arnt mRNAs, suggesting that ER-mediated estrogenic effects may be promoted by BPA. Furthermore, the estrogenic activity of BPA is increased after co-incubation with the liver to catabolize the BPA, indicating that BPA metabolite(s) may have a higher estrogenic potency than the mother compound [49-51]. We suggest that BPA itself plays a key role in the estrogenic activity of mid-stage embryos because activity for drug-metabolism in embryonic livers is extremely weak. We also suggest that both BPA and its active metabolite(s) strongly disrupt the estrogenic signals in late-stage embryos because drugmetabolism in the embryonic liver is induced by exposure to BPA.

In conclusion, this is the first paper to confirm the quantitative changes in the mRNA levels of AhR and related factors, AhRR and Arnt, and AhRmediated drug-metabolic enzymes, CYP1A1 and GST, as assessed by the quantitative RT-PCR 
method in embryonic organs (cerebra, cerebella, testes, and ovaries) during the mid- to late-stages of embryonic development. We confirmed that exposure to an extremely low dose of BPA $(0.02$ $\mu \mathrm{g} / \mathrm{kg} /$ day) in utero increased the levels of these mRNAs in embryos. Futhermore, we proposed a novel mechanism of BPA-mediated endocrine disruption in which BPA up-regulates the mRNA expression of $A h R$ and related factors. Nuclear receptors, such as $A h R$, are major targets of xenobiotic compounds and play crucial roles in embryonic development [52]. The present findings, moreover, contribute to the assessment of the toxic effects of EDs on embryogenesis.

\section{Acknowledgements}

This work was supported by a Grant-in-aid for Creative Scientific Research (13GS0008) and by a Grant-in-aid for Scientific Research (S) (16108003) to N. M. from the Japan Society for the Promotion of Science.

\section{References}

1. Sogawa K, Fujii-Kuriyama Y. Ah receptor, a novel ligand-activated transcription factor. J Biochem 1997; 122: 1075-1079.

2. Tsutsui T, Tamura Y, Suzuki A. Mammalian cell transformation and aneuploidy induced by five bisphenols. Int J Cancer 2000; 86: 151-154.

3. Papaconstantinou AD, Umbreit TH, Fisher BR, Goering PL, Lappas NT, Brown KM. Bisphenol Ainduced increase in uterine weight and alternation in uterine morphology in ovariectomized B6C3F1 mice: role of the estrogen receptor. Toxicol Sci 2000; 56: 332-339.

4. Chun TY, Gorski J. High concentrations of bisphenol A induce cell growth and prolactin secretion in an estrogen-response pituitary tumor cell line. Toxicol Appl Pharmacol 2000; 162: 161-165.

5. Laws SC, Carey SA, Ferrell JM, Bodman GJ, Cooper RL. Estrogenic activity of octylphenol, nonylphenol, bisphenol A and methoxychlor in rats. Toxicol Sci 2000; 54: 154-167.

6. An B-S, Kang SK, Shin J-H, Jeung E-B. Stimulation of calbindin- $\mathrm{D}_{9 \mathrm{k}}$ mRNA expression in the rat uterus by octylphenol, nonylphenol and bisphenol. Mol Cell Endo 2002; 191: 177-186.

7. Gaido KW, Leonardo LS, Lovell S, Gould JC, Babai D, Porter CJ, McDonnell DP. Evaluation of chemicals with endocrine modulation activity in a yeast-based steroid hormone receptor gene transcription assay. Toxicol Appl Pharmacol 1997; 1: 205-212.

8. Nagel SC, vom Saal FS, Thayer KA, Dhar MG, Boechler M, Welshons WV. Relative binding affinity-serum modified access (RBA-SMA) assay predicts the relative in vivo bioactivity of the xenoestrogens bisphenol A and octylphenol. Environ Health Perspect 1997; 1: 70-76.

9. Howdeshell KL, Hotchkiss AK, Thayer KA, Vandenbergh JG, vom Saal FS. Exposure to bisphenol A advances puberty. Nature 1999; 401:
763-764.

10. Nishizawa $\mathbf{H}$, Manabe $\mathbf{N}$, Morita $\mathbf{M}$, Sugimoto $\mathbf{M}$, Imanishi S, Miyamoto $\mathbf{H}$. Effects of in utero exposure of bisphenol A on expression of RAR $\alpha$ and $\mathrm{RXR} \alpha \mathrm{mRNAs}$ in murine embryos. J Reprod Dev 2003; 49: 539-545.

11. Mimura J, Fujii-Kuriyama Y. Functional role of AhR in the expression of toxic effects by TCDD. Biochim Biophys Acta 2003; 1619: 263-268.

12. Kanayama M, Tohyama C. Developmental neurotoxicity of dioxin and its related compounds. Indust Health 2003; 41: 215-230.

13. Baba T, Mimura J, Gradin $K$, Kuroiwa A, Watanabe T, Matsuda Y, Inazawa J, Sogawa K, Fujii-Kuriyama Y. Structure and expression of the Ah receptor repressor gene. J Biol Chem 2001; 276: 33101-33110.

14. Moriguchi T, Motohashi H, Hosoya T, Nakajima O, Takahashi S, Ohsako S, Aoki Y, Nishimura N, Tohyama C, Fujii-Kuriyama Y, Yamamoto $M$. Distinct response to dioxin in an aryl hydrocarbon receptor (AhR)-humanized mouse. Proc Natl Acad Sci USA 2003; 100: 5652-5657.

15. Hahn ME. Aryl hydrocarbon receptors: diversity and evolution. Chemico Biol Interact 2002; 141: 131160.

16. Sogawa K, Fujii-Kuriyama Y. Ah receptor, a novel ligand-activated transcription factor. J Biochem 1997; 122: 1075-1079.

17. Schmidt JV, Bradfield CA. Ah receptor signaling pathways. Annu Rev Cell Dev Biol 1996; 12: 55-89.

18. Hirose $\mathbf{K}$, Morita M, Ema M, Mimura J, Hamada $\mathbf{H}$, Fujii H, Saijo Y, Gotoh O, Sogawa K, FujiiKuriyama Y. cDNA cloning and tissue-specific expression of a novel basic helix-loop-helix/PAS factor (Arnt2) with close sequence similarity to the aryl hydrocarbon receptor nuclear translocator (Arnt). Mol Cell Biol 1996; 16: 1706-1713.

19. Shrenk D. Impact of dioxin-type induction of drug- 
metabolizing enzymes on the metabolism of endoand xenobiotics. Biochem Pharmacol 1998; 55: 11551162.

20. Nebert DW, Roe AL, Dieter MZ, Solis WA, Yang Y, Dalton TP. Role of the aromatic hydrocarbon receptor and $[\mathrm{Ah}]$ gene battery in the oxidative stress response, cell cycle control. And apoptosis. Biochem Pharmacol 2000; 59: 65-85.

21. Cauchi S, Stucker I, Cenee S, Kremers P, Beaune P, Massaad-Massade L. Structure and polymorphisms of human aryl hydrocarbon receptor repressor (AhRR) gene in a French population: relationship with CYP1A1 inducibility and lung cancer. Pharmacogenetics 2003; 13: 339-347.

22. Schmidt JV, Su GH-T, Reddy JK, Simon MC, Bradfield CA. Characterization of a murine Ahr null allele: involvement of the Ah receptor in hepatic growth and development. Proc Natl Acad Sci USA 1996; 93: 6731-6736.

23. Andreola F, Fernandez-Salguero PM, Chiantore MV, Petkovich MP, Gonzalez FJ, De Luca LM. Aryl hydrocarbon receptor knockout mice (ahr-/-) exhibit liver retinoids accumulation and reduced retinoic acid metabolism. Cancer Res 1997; 57: 2835 2838.

24. Lahvis GP, Lindell SL, Thomas RS, McCuskey RS, Murphy C, Glover E, Bentz M, Southard J, Bradfield CA. Portosystemic shunting and persistent fetal vascular structures in aryl hydrocarbon receptor-deficient mice. Proc Natl Acad Sci USA 2000; 97: 10442-10447.

25. Peters JM, Wiley LM. Evidence that murine preimplantation embryos express aryl hydrocarbon receptor. Toxicol Appl Pharmacol 1995; 134: 214-221.

26. Sharon AR, Peter JM, Ursula CD, de Luca LM. Retinoids in embryonal development. Physiol Rev 2000; 80: 1021-1054.

27. Chambon P. A decade of molecular biology of retinoic acid receptors. FASEB J 1996; 10: 940-954.

28. Chen H, Howald WN, Juchau MR. Biosynthesis of all-trans-retinoic acid from all-trans-retinol: catalysis of all-trans-retinol oxidation by human P450 cytochromes. Drug Metab Dispos 2000; 28: 315-322.

29. Inoue $\mathbf{H}$, Yokota $\mathbf{H}$, Makino $\mathbf{T}$, Yuasa $\mathbf{A}$, Kato $\mathbf{S}$. Bisphenol A glucuronide, a major metabolite in rat bile after liver perfusion. Drug Metab Dispos 2001; 29: 1084-1087.

30. Sakamoto H, Yokota H, Kibe R, Sayama Y, Yuasa A. Excretion of bisphenol A-glucuronide into the small intestine and deconjugation in the cecum of the rat. Biochim Biophys Acta 2002; 1573: 171-176.

31. Matsumoto J, Yokota H, Yuasa A. Developmental increases in rat hepatic microsomal UDP-glucuronosyltransferase activities toward xenoestrogens and decreases during pregnancy. Environ Health Perspect 2002; 110: 193-196.

32. Carver LA, Bradfield CA. Ligand-development interaction of the aryl hydrocarbon receptor with a novel immunophilin homolog in vivo. J Biol Chem 1997; 272: 11452-11456.

33. Andersson P, McGuire J, Rubio C Gradin K, Whitelaw ML, Pettersson S, Hanberg A, Poellinger L. A constitutively active dioxin/aryl hydrocarbon receptor induces stomach tumors. Proc Natl Acad Sci USA 2002; 99: 9990-9995.

34. Abbott BD, Birnbaum LS, Perdew GH. Developmental expression of two members of a new class of transcription factors: I. expression of aryl hydrocarbon receptor in the C57BL/6N mouse embryo. Dev Dyn 1995; 204: 133-143.

35. Abbott BD, Schmid JE, Pitt JA, Buckalew AR, Wood CR, Held GA, Diliberto JJ. Adverse reproductive outcomes in the transgenic Ah receptor-deficient mouse. Toxicol Appl Pharmacol 1999; 155: 62-70.

36. Imanishi S, Manabe $\mathbf{N}$, Nishizawa $\mathbf{H}$, Morita $\mathbf{M}$, Sugimoto M, Iwahori M, Miyamoto $\mathbf{H}$. Effects of oral exposure of bisphenol A on mRNA expression of nuclear receptors in murine placentae assessed by DNA microarray. J Reprod Dev 2003; 49: 329-336.

37. Nishizawa $H$, Morita $M$, Sugimoto $M$, Imanishi $S$, Manabe N. In utero exposure to bisphenol A on mRNA expression of aryl hydrocarbon and retinoid receptors in murine embryos. J Reprod Dev 2005; 51: 315-324.

38. Komatsu K, Manabe N, Kiso M, Shimabe M, Miyamoto H. Soluble Fas (FasB) regulates luteal cell apoptosis during luteolysis in murine ovaries. $\mathrm{Mol}$ Reprod Dev 2003; 65: 345-352.

39. McClive PJ, Sinclair AH. Rapid DNA extraction and PCR-sexing of mouse embryos. Mol Reprod Dev 2001; 60: 225-226.

40. Tsutsumi O. Effects of endocrine disruptors on preimplantation embryo development. Nippon Rinsho 2000; 12: 2464-2468.

41. Funabashi T, Sano A, Mitsushima D, Kimura F. Bisphenol A increases progesterone receptor immunoreactivity in the hypothalamus in a dosedependent manner and affects sexual behavior in adult ovariectomized rats. J Neuroendocrinol 2003; 15: 134-140.

42. Dupe V, Ghyselinck NB, Wendling O, Chambon $\mathbf{P}$, Mark M. Key roles of retinoic acid receptor- $\alpha$ and $-\beta$ in the patterning of the caudal hindbrain, pharyngeal arches and otocyst in the mouse. Development 1999; 126: 5051-5059.

43. Pauken CM, LaBorde JB, Bolon B. Retinoic acid acts during peri-implantational development to alter axial and brain formation. Anat Embryol 1999; 200: 645-655.

44. Wendling O, Chambon P, Mark M. Retinoid X receptors are essential for early mouse development and placentogenesis. Proc Natl Acad Sci USA 1999; 96: 547-551. 
45. Rendic S. Summary of information on human CYP enzymes: human P450 metabolism data. Dug Metab Rev 2002; 34: 83-448.

46. Gould JC, Leonard LS, Wagner BL, Conner K, Zacharews T, Safe S, McDonnell DP, Gaido KW. Bisphenol A interacts with the estrogen receptor $\alpha$ in a distinct manner from estradiol. Mol Cell Endocrinol 1998; 142: 203-214.

47. Hiroi H, Tsutsumi O, Momoeda M, Takai Y, Taketani Y. Differential interactions of bisphenol A and $17 \beta$-estradiol with estrogen receptor (ER) $\alpha$ and ER $\beta$. Endocr J 1999; 46: 773-778.

48. O'Hara PJ, Sheppard PO, Thogersen H, Venezia D, Haldeman BA, McGrane V, Houamed KM, Thomsen C, Gilbert TL, Mulvihill ER. The ligandbinding domain in metabotropic glutamate receptors is related to bacterial perplasmic binding proteins. Neuron 1993; 11: 41-52.
49. Yoshihara S, Mizutare T, Makishima M, Suzuki N, Fujimoto N, Igarashi K, Ohta S. Potent estrogenic metabolites of bisphenol A and bisphenol B formed by rat liver $S 9$ fraction: their structures and estrogenic potency. Toxicol Sci 2004; 78: 50-59.

50. Poskrobko J, Dejnega $\mathbf{M}$, Kiedik $\mathbf{M}$. Highperformance liquid chromatography with multiwavelength detection of the bisphenol A impurities. J Chromatogr A 2000; 883: 291-297.

51. Rivas A, Lacroix M, Olea-Serrano F, Laios I, Leclereq G, Olea N. Estrogenic effects of a series of bisphenol analogues on gene and protein expression in MCF-7 breast cancer cells. J Steroid Biochem Mol Biol 2002; 82: 45-53.

52. Gronemeyer H, Gustafsson JA, Laudet V. Principles for modulation of the nuclear receptor superfamily. Nature Rev Drug Discov 2004; 33: 950964. 